\title{
Status of the Engineering Students' English in Bangladesh: A Case Study
}

\author{
Md. Iftekhar Arafath ${ }^{1 *}$ Mohammad Rukanuddin ${ }^{2}$ \\ 1. Department of Arts and Sciences, Ahsanullah University of Sciencs and Technology, 141-142 Love \\ Road, Tejgaon Industrial Area, Dhaka-1208, Bangladesh
}

2. Department of Arts and Sciences, Ahsanullah University of Sciencs and Technology, 141-142 Love Road, Tejgaon Industrial Area, Dhaka-1208, Bangladesh

\begin{abstract}
Bangladesh is a rapidly growing economy where English plays a vital role in many development sectors that contribute to the development of the country. Bangladesh has to communicate with many nations of the world for business, education, foreign expertise, researches and so on. Competent engineers in various disciplines hold important position in varied development work of the country. Engineers who can communicate in English well can contribute much to his personal career as well to the nation. So, engineers while studying engineering subjects should also be serious about learning the English language. For this reason, English is to be taught in the tertiary level engineering institutions with utmost importance. The article explores the condition of English among the students studying engineering in Bangladesh by studying the recent literature and a survey of samples taken from students' examination scripts, listening tests, speaking tests, and reading tests. All these things reveal that the teaching and learning activities in English are not up to the standard required for engineering students.
\end{abstract}

Keywords: competent engineers, tertiary level, examination scripts, teaching and learning

DOI: $10.7176 / \mathrm{JLLL} / 55-11$

Publication date: April $30^{\text {th }} 2019$

\section{Introduction}

As communication matters a lot in any profession as well as in personal and social life, utmost importance should be given in the teaching and learning a language that is indispensable and unavoidable in the globalization context. And unequivocally, this language, in the present day context, is the English language. The significance and necessity of learning English are realized by all conscious people of this time.

According to Lee (2018) in the 21st century, effective use of the English language has become a major issue in this age of globalization. Most of the nations of the globe have to interact with one another. He adds that with the initiation of digital communication, English as a global language has further extended to the far off lands. Moreover, English has become the language of business around the world. So, he argues that if anyone plans to pursue a career that requires international interactions and cooperation, he should learn English without delay. Here the researcher has tried to clarify the need and importance of becoming proficient in English in the global context not only for any particular nations.

Shrestha, et al. (2015) state, "People involved in diverse fields and professions use it as a means of communication to acquire information, clambering the ladder in their academic field, and reaching the summit of success in their endeavors, conducting researches, publishing their research findings and executing their duties in their respective areas of work".

Like every other field of education, profession and business, in the field of engineering whether it is in the engineering profession or engineering education, knowing and being able to use English proficiently is a must. Engineers should be able to use English for acquiring knowledge from books, journals, the Internet and other sources, publishing their research articles, giving oral presentations in seminars and conferences, and for communicating with fellows, coworkers and clients (Shrestha, et al.). Reimer (2002) in Shrestha, et al. (2015) observes that for engineers who intend to carry out their professional duties in the globalised perspective, communication skills are essential. He clarifies that engineering communication skills are nothing but several 'core elements' of English language like fluency in the use of English and the basics of visual communication.

There is no denying the fact that communication skills are essential for all kinds of engineers. Whatever academic qualification they might have, they must be highly proficient in communication in English. Thaky (2014) says, "Lack of sufficient communication skills serves only to undermine the image of the engineer." As competent engineers, they need to have communication with various types of clients, academics, in both their 
home country and abroad. If they fail to communicate properly, that will be a shame for them.

Gupta (2013) asserts that engineering candidates who have good English communication skills and soft skills become successful in their academic as well as professional career. On the other hand, she argues, those who do not possess those skills become victims of depression and frustrations. This is true to the strictest sense of the expression in Bangladesh perspective also. It is observed here that many engineers with requisite qualifications sometimes remain unemployed or underemployed for long because of not having required command in English language. In contrast, engineers with the same academic qualifications having proficiency in English enjoy high paying jobs in reputed organizations.

Huckin \& Olsen (1991) point out that though the scientists and engineers are technically 'brilliant and creative', their technical skills will be meaningless and thus will remain 'unnoticed, unappreciated, and unused' if they cannot communicate convincingly with 'co-workers, clients and their supervisors'. They in this perspective add that 'communication skills are not just useful; they are critical tools for success, even for survival in real world environments'. And here it is implied that communication skills mean communication skills in the English language.

In Bangladesh context, English plays significant roles in all steps of our education from pre-primary to highest level. English is used in various professional fields as a common means of communication here. People know that knowing more English is getting more success here in this country. Regarding the use of English in Bangladesh, Maniruzzaman (1998) says:

"In reality the English language is necessarily being used in all the sectors of Bangladesh, such as offices, courts, educational institutions, press, and even sometimes in parliament. This is because English is not now only the language of English and the United States, but is also spoken and studied or read by the largest number of people, and has been recognized as a second or foreign language throughout the world. Despite being a foreign language officially, the English language is indeed enjoying the status of a second language to a limited extent in the activities of the educated people, particularly in the urban areas of Bangladesh" (p.6).

It is obvious that English is a necessity for all including the engineering students of Bangladesh. Now, the question arises whether people with engineering profession possess the proficiency required for the profession. Moreover, it is also to be seen whether English language teaching and learning are given proper importance in our engineering curricula, and if not, the pitfalls and problems should be explored.

Hossain (2013) reports after conducting a linguistic research on the engineering students of a private university that though the engineering students had previous experiences of learning English for about twelve years, their level of proficiency in English was not so good. They were found deficient in most of the skills of English and therefore they needed to learn various technicalities of linguistic communication in English.

As practicing academics in the field of English language teaching we have witnessed and experienced many problems in teaching and learning of English in the engineering education sector. And in support of this view, Hassan \& Mostafa (2016) testify to the fact that no organized or experiential researches have been carried out so far in Bangladesh to evaluate the English language needs of our engineering students. They add that the courses that were implemented were never evaluated by the relevant authority. And this is why, the researchers argue, the courses ultimately could not bring success. So, further researches on the status of English of the engineering students are a necessity.

\section{Problems Faced by Teachers}

Engineering students in Bangladesh are taught four basic skills of English language--reading, writing, listening and speaking--with a focus on communication skills. English language teachers of engineering students complain quite frequently that the students do not give as much importance to English language as they give to their engineering subjects. Because of this negligence, they develop some weak areas in basic language skills, particularly, vocabulary, speaking skills and use of grammar. This becomes apparent when interviewers of jobs in different companies report that the applicants fail to satisfy the interviewers in job interviews because they lack communication skills. Zaman (2007) points out this particular situation for the graduates of Computer Science and Engineering,

"Despite this high demand, a large number of CSE graduates are still unemployed. In most of the cases, these graduates are found 'not employable' after selection process. Quite frankly, these unfortunate graduates seriously lack the very basic knowledge of problem solving, English language, communication, programming and software engineering." 
In present job market there is a very high demand for communication skills and so English language skills of the engineering students have to be improved using the most effective methods of teaching. Hasan (2019) has identified this particular situation,

"The training given to students in universities is not focused on the industry's requirements. As a result, corporate bodies and factory owners are forced to bring in personnel from overseas. They allege that there exists a dearth of technical, professional and language skills that are regarded as prerequisites in the fast-changing job market in the era of the fourth industrial revolution."

English language teachers of engineering institutions face both academic and non-academic problems. The first problem they face is the time frame of their course. They argue that the time they get for teaching their course is not sufficient. It is almost impossible to improve English language skills of the students within this short period. The duration of class is also a barrier for teaching language skills. The teacher gives a task to the students. Some students are fast learners and they complete the task in the given time. There are some slow students in the class who find it difficult to complete the task in stipulated time and they wait for their teacher to provide answers after the given time is over. This is a general observation of the teachers that the weak students take almost three times more time than the fast students (Gupta, 2013). This is not an ideal situation for teaching English language skills.

The second problem the teachers of English language face is that they get students of different levels of linguistic proficiency, motivation and ability of grasp. There is no standard screening for linguistic proficiency of engineering students which makes it absolutely painful for an English language teacher to guide all his students towards achieving one goal. Some students find the activities of class very conducive while some others find them boring which may make them passive in the class. In order to get more positive results in teaching English language skills, engineering students have to be graded according to their linguistic proficiency. Then the teacher will be able to carry out activities in the class more effectively while the students will also enjoy the class activities and learn more effectively. In Bangladesh proficiency in English mainly depends on the background study of the students. According to a study conducted by Imam (2005), average level of English language skills of university students is equivalent to that of class 7 students. Chowdhury \& Kamal (2014) identify that though primary and secondary level students study English as a compulsory subject, their performance in English is generally very poor. The students who studied their secondary and higher secondary levels at renowned schools and colleges of major cities generally have better linguistic competence than the students who studied in remote areas. Attending an English medium school and college also has a positive correlation with a better linguistic proficiency. However, English language proficiency is not a major criterion in the admission process of engineering students in Bangladesh.

There is a high corporate demand for engineers in Bangladesh though the statistics says that the number of unemployed engineers is increasing day by day. International demand for engineers is also increasing but it is not changing the unemployment scenario for our engineering graduates. There is a paradoxical situation prevailing here - the queue of unemployed engineers is getting longer and longer while the large corporate houses repeatedly complain that they do not find qualified applicants for giving jobs. Zaman (2007) explains this situation,

"Almost all of these graduates are from the Private Universities in Bangladesh and India. So they remain unemployed having a CSE or relevant degree, even though we have serious shortage for fresh competent graduates. This is a sad situation for both the parties: we are looking for people, and they are looking for jobs; yet we cannot offer jobs to them!"

The human resource departments of corporate houses generally question the English language proficiency and communication skills of the applicants. This situation automatically demands more attention on the teaching of English language and communication skills at engineering institutions.

Proficiency in English language is an essential qualification of getting a respectable career in Bangladesh. It can also open many doors and windows in global job market. So English language is directly related with employability. English language courses taught to engineering students at tertiary level in Bangladesh are basically general English courses. They are not tailored for satisfying the needs of engineers. Though some universities have recently introduced English courses with a focus on communication skills, their goals are not well defined and therefore the methodology of teaching, testing and evaluating are not appropriate. Engineering students who attempt to admit to international engineering universities abroad for higher studies suffer the lack of communication skills. 


\section{Problems Faced by Students}

Passing the Higher Secondary Certificate examination, students come to study engineering. Biswas (2014) mentions "It is now considered that level of English language in local higher secondary passed students is poor and thus is not sufficient for technical education." The medium of instruction at secondary level is mainly the mother tongue, Bangla. At English medium and English version the medium of instruction is English. Most of the students in Bangladesh study in Bangla medium institutions. This background plays a big role in teaching English to engineering students at tertiary level. The medium of instruction at tertiary level engineering institutions is English. So, now the students are bound to engage themselves in reading text books, listening to the lectures of course teachers, writing in final exams and other tutorials and quizzes and asking questions in English. Students' background knowledge in English now becomes extremely valuable in understanding the topics taught, doing well in examinations and expressing themselves. Students come to engineering institutions at tertiary level with a variety of English language proficiency. It is generally observed that students from English Medium and English Version background perform better than students coming from Bangla Medium background. Again, if the linguistic proficiency of only Bangla Medium students is considered, it is clearly evident that students coming from renowned colleges of urban areas perform much better than the students coming from other less famous colleges of urban areas and rural areas. When a teacher of English language at a tertiary level engineering institution finds students of different linguistic proficiency where some students are doing very well and some others are doing very bad, it becomes very difficult for the teacher to achieve the goal of his/her course. Ur (1996) mentions this situation by explaining that in a large class where there are students of different levels of linguistic competence, some students find the materials used in the class easy and some other students find the same materials difficult to understand.

Number of students in a class is another problem of learning and teaching English at tertiary level engineering institutions in Bangladesh. The ideal number of students in a language class is $10-20$. Anderson (2016) says, "Teachers working in private language schools in Europe may expect classes of ten to 15; for them 20 is often seen as too large." But it is not possible to find only 20 students in an engineering institution at tertiary level in Bangladesh. Because of a big population and education policy a lot of students very often come to study engineering at tertiary level. It is literally impossible to keep only 20 students in a class. These students have come to study engineering, not English and so the teachers of English fail to convince the authorities of engineering institutions to keep only 20 students in a class - at least in an English language class. There are very often more than 50 students in a class. In a big class it becomes absolutely impossible for the teacher to give attention to each individual student (Le, 2002) and check everybody's performance in stipulated time. So, what happens in the class is that the teacher checks the scripts of only a few students who perform quickly and better; the weaker students tend to lose interest and they wait for the teacher to give the solutions to the problems given.

Syllabus of English courses at tertiary level engineering institutions is the next problematic issue. Most of the syllabi of English courses are of general English. They focus on the continuation and repetition of the topics learned by the students in schools and colleges. In professional life engineers need specific uses of English which are not considered while designing syllabus of English courses for engineering students. Only a few private universities are now designing their syllabus of English courses on the basis of a needs analysis. All other tertiary level engineering educational institutions should think in the same way. Students would be more motivated if they got more relevant topics in their English language courses (Hassan \& Mostafa, 2016).

Students of tertiary level engineering institutions also face the problem of lack of exposure. Though English is an international language which is used in almost all the communication at international level, it has the status of foreign language in Bangladesh which means it is not used as the medium of communication in everyday life in Bangladesh (Hassan, 2011). This particular situation hinders our English language learners of all levels from using English in real life which is a big barrier for learning any second or foreign language. This lack of exposure strengthens the inhibition in our students which prevents them from using English in real life situations and even in language classrooms.

\section{Methods}

Survey method was followed to collect data for the study. Data were collected from the samples of 75 tertiary level students of EEE, CSE and IPE of Ahsnaullah University of Science and Technology, Dhaka. The samples were taken from the scripts of writing class tests, reading tests, listening tests and the results of speaking tests. The data analysis has been given below: 


\section{Pitfall of Writing}

After the scripts of the students of EEE, CSE and IPE departments were scrutinized, following major types of errors were found:

\subsection{Sequence of Tenses}

This is the most common type of error that students committed. 63 out of 75 scripts had this error. Students report that in schools and colleges they learned the structures of different tenses very precisely. If teachers tell them to produce the structures of different tenses, they will be able to do that along with examples. But when they are told to use those structures in real life situation, they feel quite hesitated and ultimately many of them remain silent. The focus of learning English in schools and colleges was form, not the uses which needs to change. However, lack of exposure is a big obstacle in this case.

\section{2 Structures}

By structure we mean the sequence of words in a sentence. This is another area that needs attention. It seemed from the scripts that some of the students are trying to use the sentence structures on their own. Their mother tongue plays a very significant role in this particular case. When they do not know the appropriate structure of a sentence, they are trying to imitate the structures from their mother tongue. This type of mistakes was found in 49 scripts.

\section{3 Spellings}

Errors in spelling are the next area of concern. In 46 scripts spelling errors were found. In some of the scripts this error was very frequent. The students attributed this error to the use of different social media. They say that most of them remain very busy in social media and they do not care of the spelling while they use these media. When they write answers in the exams, spelling from their social media appear which in many cases are not correct.

\section{4 Coherence (Use of Connectors)}

Coherence is the bond between and among sentences that bind them together. Scrutiny of students' scripts gave us an insight that the students seriously lack the sense of connection between and among sentences. Some students used minimum number of connectors. However, 12 scripts had no connecting words at all.

\section{5 Sense of Paragraph}

Careful structural writing draws the attention of readers. Paragraphing helps a writer express the ideas in a more organized fashion. There is a lack of sense of paragraph among the students which needs to be addressed.

\section{Reading}

Students' performance in reading comprehension indicates that 'authentic materials' should be used while teaching reading skills to engineering students of tertiary level. A comparison between the writing styles of native English users in workplace and texts of published books may help these students in developing their vocabulary and structures that are necessary in professional career.

\section{Speaking}

The major problem that deters engineering students of tertiary level from speaking fluently in English is inhibition. They are afraid of making mistakes in front of others and being criticized by others. The other drawback of speaking English is that while speaking in English the students think in their mother tongue first and they try to translate that thinking in English which make the process slow and ultimately they lose interest. All these things can be overcome, in most of the cases, by exposing the students to English. They need more opportunity to use English in their conversations. 


\section{Listening}

The students who have habits of listening to English conversations performed better in listening tests. Some of the students developed this listening skill by listening to English songs and lectures and others by watching English films. Some of the students who completed their secondary and higher secondary level of education do not understand the simplest sentences uttered by English native speakers. Even, if the tape scripts of the listening lessons are given prior to the listening tests, they fail to perform. For example in the authors' English lab classes the audio lessons given in the New Headway Intermediate $3^{\text {rd }}$ ed (Liz and Soars, ) were given to the students along with the tape scripts for practice, but practicing for two three weeks about 30 percent students fail to obtain the pass marks in the tests.

\section{Conclusion}

From the data analysis it is clear that the status of engineering students' English in Bangladesh is not commendable at all. The teaching and learning of English in the tertiary level engineering classes are to be reorganized and reshaped in order to streamline the English language teaching in this sector.

\section{Suggestions}

In view of the findings of the study we would like to propose a number of suggestions in order to boost up the Engineering students' condition of English studies. (i) first and foremost, there should be appropriate syllabus designned according to the needs of the students. Next, in designing the syllabus, English for Academic Purpose (EAP) rules should be followed. Moreover, it should be ensured that the teachers teaching English should have appropriate training in teaching English. Bodies overseeing the universities, should have set rules for syllabus and curriculum for every discipline.

\section{References}

Anderson, J. (2016), "What to consider when teaching English in large classes", The British Council, https://www.britishcouncil.org/voices-magazine/what-consider-when-teaching-english-large-classes. Retrieved 26 March 2019.

Biswas, S. K. (2014), "Problems of Tertiary Engineering Education of Bangladesh and some suggestions for possible improvements", International Conference on Mechanical, Industrial and Energy Engineering 2014, 25-26 December, 2014, Khulna, BANGLADESH.

Chowdhury R, Kamal M. (2014), "Balancing conformity and empowerment: the challenges of critical needs analysis in an EAP course at Dhaka University", English for Academic Purposes in Asia: Negotiating Appropriate Practices in a Global Context. Edited by: Liyanage I, Walker T. Sense Publishers, Rotterdam; 2014:79-92. 10.1007/978-94-6209-752-0_6

Gupta, D. (2013), “Teaching English to Engineering Students in India”, Journal of Education and Practice. 4(11), 131-138.

Hassan, K. \& Mostafa, K. A. (2016), "ESP and Needs Analysis: Teaching English to Engineering Students in Bangladesh", MIST Journal of Science and Technology. 4, 26-36.

Hassan, M. M. (2011), "English in Bangladesh as a Corporate Language: Problems and Solutions", East WestUniversity,http://dspace.ewubd.edu/bitstream/handle/123456789/646/Mohammad_Mahmudul_Hasa n.pdf? sequence=1\&isAllowed=y. Retrieved on 26 March 2019.

Hossain, M.J. (2013), “ESP Needs Analysis for Engineering Students: A Learner Centered Approach”, Journal of $P U$, Part: B, 2 (2), 16-26.

Huckin, T. N., \& Olsen, L. A. (1991), Technical Writing and Professional Communication for Nonnative Speakers of English. McGraw-Hill International Editions, Page 3.

Imam, S. R. (2005), "English as a global language and the question of nation-building education in Bangladesh", Comparative Education, 41 (4): 471-486. doi:10.1080/03050060500317588.

Khalid H. (2019), "Why are university graduates failing to meet market needs?", The Daily Star, January 14, 2019 Retrieved from https://www.thedailystar.net/opinion/education/news/why-are-university-graduatesfailing-meet-market-needs-1686997 on 21 March, 2019 at 12:17 pm 
Le, P. K. (2002), "Problems, Solutions and Advantages of Large Classes", Teacher's Education, September 2002 , 8-11

Lee, A. (2018), "Why English Matters and Why Your should Care", Retrieved 23 November 2018 https://forcemedia.org/news/2018/3/26/why-english-matters-and-why-you-should-care

Maniruzzaman, M. (1998), “A Socio-Psycholinguistic Study of the Interaction between Attitudes and Motivation of Undergraduates and their Proficiency in EFL", Ph.D. Thesis, University of Dhaka: Bangladesh

Reimer, M.J. (2002), "English and Communication Skills for the Global Engineer", Global Journal of Engineering Education, Australia. In Shrestha, R, N., Pahari, B, R., \& Awasthi, J. R. (2015)

Shrestha, R. N., Pahari, B, R., \& Awasthi, J. R. (2015), "Impact of English on the Career of Engineering Students: A Brief Overview in G(local) Context”. Journal of the Institute of Engineering, 2015, 11(1), $182-188$

Thaki, P. (2014), "Importance of English and Communication Skills for Technical Professionals", International Journal of Scientific Research. 3(4), 211.

Ur, P. (1996), A Course in Language Teaching: Practice and Theory. Cambridge University Press.

Zaman, F. (2007), "The CRISIS for Software Professionals in Bangladesh”, BASIS News \& Views. 3(4), 1-3, Retrieved from https://basis.org.bd/newsletter/bc751736a42a7c1b4a9a9ebf9fc12d8c.pdf On 15 January $\underline{2019}$ at 2:02 pm. 